\title{
Ocorrência de nematóides fitoparasitos em solo cultivado com algodão e soja
}

\author{
Amanda Casagrande Pereira1, Luciana Claudia Toscano ${ }^{1}$, Alexandra Botelho Abreu², Noemi \\ Souza Vieira ${ }^{1}$, Pamella Mingotti Dias ${ }^{1}$
}

\author{
${ }^{1}$ Universidade Estadual de Mato Grosso do Sul, UEMS, Unidade Universitária de Cassilândia, Mato Grosso do Sul, Brasil. E-mail: \\ amanda_tanabi@hotmail.com,no-cristina@hotmail.com,pamellamingotti@hotmail.com \\ ${ }^{2}$ Fundação de Apoio à Pesquisa Agropecuária de Chapadão do Sul, Mato Grosso do Sul, Brasil. E-mail: \\ alexandrablabreu@hotmail.com
}

Recebido: 14/08/2015; Aceito: 24/11/2015.

\section{RESUMO}

O objetivo da pesquisa foi identificar a dinâmica populacional das espécies de nematóides nas culturas de algodão e soja em Cassilândia-MS. O experimento foi instalado na Universidade Estadual de Mato Grosso do Sul (UEMS), em duas áreas com $500 \mathrm{~m}^{2}$ para cada cultura. As coletas de solo e raiz foram realizadas a cada 15 dias desde o início até o término das culturas, totalizando oito coletas. As amostras coletadas foram encaminhadas para o laboratório da Fundação Chapadão, em Chapadão do Sul-MS. Os nematóides identificados nas culturas foram dos gêneros Pratylenchus, Meloidogyne, Heterodera, Helicotylenchus, Mesocriconema, sendo a maior população encontrada para o gênero Pratylenchus, variando de 10 a 100 indivíduos $/ 100 \mathrm{~cm}^{3}$ de solo para nos cultivos de soja e algodão. Quanto à ocorrência nas raízes houve variação de 560 a 5100 indivíduos/10 g para a soja, e de 70 a 2400/10 g para algodão. Os nematóides encontrados nas culturas de algodão e soja foram: Pratylenchus sp., P. zeae, P. brachyurus e Heterodera sp. O gênero Helicotylenchus sp. infectou somente o algodão e Meloidogyne sp. e Mesocriconema sp. exclusivamente a cultura da soja.

Palavras-chave: Fitonematóides, Helicotylenchus, Pratylenchus, Heterodera, Meloidogyne.

\section{Occurrence plant- parasitic nematodes in soil under cotton and soybean cropping system}

\begin{abstract}
The objective of the research was to identify the population dynamic of nematode species under cotton and soybean cropping systems in Cassilândia, MS, Brazil. The experiment was conducted at Universidade Estadual de Mato Grosso do Sul (UEMS), in two areas with $500 \mathrm{~m}^{2}$ for each crop. Soil sampling and root were taken every 15 days from the beginning to the end of the cropping, totaling eight samples. The collected samples were sent to the laboratory of Fundação Chapadão in Chapadão do Sul-MS. The genera Pratylenchus, Meloidogyne, Heterodera, Helicotylenchus, Mesocriconema were identified in both areas. The largest population was found for the genera Pratylenchus, ranging from 0 to 100 individuals $/ 100 \mathrm{~cm}^{-3}$ of soil to cotton and soybean cropping systems. As regards the variation occurring in the roots was 560 to 5100 nematodes $/ 10 \mathrm{~g}$ of soybean root, and 70 to 2400 nematodes $/ 10 \mathrm{~g}$ of cotton root. Results reported that the nematodes found in soybean and cotton crops were: Pratylenchus sp, P. zeae, P. brachyurus and Heterodera sp. The genera Helicotylenchus sp. only infected cotton cropp and Meloidogyne sp. and Mesocriconema sp. only infected soybean cropp.
\end{abstract}

Key words: Nematodes, Helicotylenchus, Pratylenchus, Heterodera, Meloidogyne. 


\section{Introdução}

A cultura do algodão e da soja exerce um papel importante no desenvolvimento da economia brasileira. De acordo com a Conab (2015), a área cultivada de algodão referente à safra 2014/15 foi de 977,7 mil hectares, com produção de 1,5 milhões de toneladas. A soja segue em expansão territorial ocupando o equivalente a 31,9 milhões de hectares e apresentando incremento de produtividade a cada safra, visto que na safra de 2014/15 obteve produção de 96 milhões de toneladas (CONAB, 2015).

Durante o desenvolvimento fenológico das culturas algodão e soja vários são os fatores que podem afetá-las negativamente, destacando os fitonematóides causadores de danos econômicos, pois prejudicam a absorção de água e nutrientes causando a diminuição da produtividade. As principais espécies de nematóides causadoras de danos em soja são as formadoras de galhas Meloidogyne javanica (TREUB, 1885) Chitwood (1949); M. incognita (KOFOID, WHITE, 1919) Chitwood (1949) e M. arenaria (NEAL, 1889) Chitwood (1949); o nematoide de cisto da soja (NCS) Heterodera glycines Ichnohe (1952); o nematoide reniforme Rotylenchulus reniformis (LINFORD; OLIVEIRA, 1940) e o nematoide das lesões Pratylenchus brachyurus (GODFREY, 1929) Filipjev e Schurmans Stekhoven (1941) (INOMOTO, 2006). Essas espécies têm sido constatadas em diferentes regiões brasileiras principalmente na região Central, onde o problema é crescente, apresentando danos severos em lavouras de Mato Grosso do Sul e Goiás (EMBRAPA, 2011).

Em relação à cultura do algodoeiro, há três espécies de nematóides com maior ocorrência no Brasil, o $M$. incognita, $R$. reniformis e o P. brachyrus, no entanto estes parasitas também são prejudiciais à soja, o que aumenta o potencial de risco para regiões de cultivo contínuo com culturas suscetíveis (ASMUS, 2004).

Para se tomar medidas eficazes de controle dos nematóides é imprescindível considerar não apenas a espécie do patógeno, mas também o quanto deste está presente na área. O estudo da dinâmica populacional é uma ferramenta importante, pois gera informações que contribuem para o estabelecimento de medidas de controle visando a interrupção do ciclo de vida dos nematóides e a diminuição do potencial de inóculo (DAVIDE, 2003).

O objetivo do trabalho foi identificar as espécies de nematóides e quantificar sua população em solo cultivado com algodão e soja.

\section{Material e Métodos}

O experimento foi conduzido na safra de 2011/12 no período de dezembro a abril, na Universidade Estadual de Mato Grosso do Sul (UEMS), Unidade Universitária de Cassilândia-MS (UCC), localizada na latitude de $19,1225^{\circ}$, longitude de $-51,7208^{\circ}$ e altitude de $516 \mathrm{~m}$. De acordo com a classificação climática de Köppen, o clima é tropical chuvoso (Aw), com verão chuvoso e inverno seco (precipitação de inverno menor que $60 \mathrm{~mm}$ ). O solo da área experimental segundo EMBRAPA (1999) é classificado como Neossolo Quartzarênico, com as características químicas descritas na Tabela 1.

Tabela 1. Propriedades químicas do Neossolo Quartzarênico. Cassilândia, MS. 2011.

\begin{tabular}{|c|c|}
\hline Propriedades & Valor \\
\hline $\mathrm{pH}$ em $\mathrm{CaCl}_{2}$ & 4,8 \\
\hline $\mathrm{P}\left(\mathrm{mg} \mathrm{dm}^{-3}\right)$ & 7,0 \\
\hline $\mathrm{K}\left(\mathrm{cmol}_{\mathrm{c}} \mathrm{dm}^{-3}\right)$ & 1,4 \\
\hline $\mathrm{S}\left(\mathrm{mg} \mathrm{dm}^{-3}\right)$ & 8,0 \\
\hline $\mathrm{Ca}\left(\mathrm{cmol}_{\mathrm{c}} \mathrm{dm}^{-3}\right)$ & 7,0 \\
\hline $\mathrm{Mg}\left(\mathrm{cmol}_{\mathrm{c}} \mathrm{dm}^{-3}\right)$ & 3,0 \\
\hline Soma de Bases $\left(\mathrm{cmol}_{\mathrm{c}} \mathrm{dm}^{-3}\right)$ & 11,4 \\
\hline $\mathrm{Al}\left(\mathrm{cmol}_{\mathrm{c}} \mathrm{dm}^{-3}\right)$ & 2,0 \\
\hline Acidez potencial $\left(\mathrm{cmol}_{\mathrm{c}} \mathrm{dm}^{-3}\right)$ & 15,0 \\
\hline $\mathrm{CTC}\left(\mathrm{cmol}_{\mathrm{c}} \mathrm{dm}^{-3}\right)$ & 31,4 \\
\hline Saturação por $\mathrm{Al}(\%)$ & 20,0 \\
\hline Saturação por bases $(\%)$ & 44,0 \\
\hline Matéria orgânica $\left(\mathrm{g} \mathrm{dm}^{-3}\right)$ & 12,0 \\
\hline $\mathrm{Mg} / \mathrm{CTC}(\%)$ & 10,0 \\
\hline $\mathrm{Ca} / \mathrm{CTC}(\%)$ & 22,0 \\
\hline
\end{tabular}

As culturas de soja e algodão foram instaladas em uma área de $1000 \mathrm{~m}^{2}$, sendo dividida em $500 \mathrm{~m}^{2}$ para cada cultura. Anteriormente ao plantio a cultura predominante no terreno era o capim braquiária (Brachiaria spp.).

A parcela experimental foi constituída de 10 metros de largura por 50 metros de comprimento, sendo utilizado a cultivar de soja BMX Potência RR com resistência ao cancro da haste, podridão radicular e suscetível aos nematóides de cisto e galhas (BRASMAX GENETICA, 2013). A semeadura foi realizada no espaçamento de 0,45 metros entre fileiras, com densidade de semeadura 266.666 sementes ha $^{-1}$. No algodão foi utilizada a cultivar convencional FMT 701 que, de acordo com Aguiar (2007), apresenta resistência à virose, bacteriose, à ramulária, ramulose e aos nematóides do gênero Meloidogyne; foi semeada no espaçamento de 0,90 metros entre fileiras, com densidade de semeadura 111.111 sementes $\mathrm{ha}^{-1}$.

A implantação das culturas foi realizada através do sistema de plantio direto com a semeadora de cinco linhas KF 5030-H. Após o plantio foi realizado uma aplicação pré-emergente utilizando glifosato visando eliminar plantas invasoras na área.

$\mathrm{Na}$ adubação de semeadura para a cultura da soja foi de MAP para o suprimento de nitrogênio, fosforo e potássio sendo $10 \mathrm{~kg}$ de $\mathrm{N} \mathrm{ha}^{-1}, 106 \mathrm{~kg}$ de $\mathrm{P}_{2} \mathrm{O}_{5}$ e $50 \mathrm{~kg}$ $\mathrm{K}_{2} \mathrm{O}$ ha $^{-1}$ respectivamente. Em algodão foi utilizado o mesmo fertilizante MAP, fornecendo $20 \mathrm{~kg} \mathrm{ha}^{-1} \mathrm{de} \mathrm{N}, 80$ 
$\mathrm{kg} \mathrm{ha}^{-1}$ de $\mathrm{P}_{2} \mathrm{O}_{5}$ e $40 \mathrm{~kg} \mathrm{ha}^{-1}$ de $\mathrm{K}_{2} \mathrm{O}$ ha- ${ }^{-1}$. A adubação de cobertura foi realizada manualmente apenas na cultura do algodão com 30 dias após o plantio, utilizando como fonte a ureia na dosagem de $40 \mathrm{~kg} \mathrm{ha}^{-1}$ de $\mathrm{N}$.

Para as análises nematológicas, as coletas de solo e raízes foram realizadas na área experimental onde cada amostra composta foi formada por três amostras simples devidamente homogeneizadas, contendo $500 \mathrm{~g}$ de solo e $10 \mathrm{~g}$ de raízes. As coletas foram iniciadas no dia do plantio e terminaram no início da colheita; para cada cultura foram realizadas oito análises com intervalo de 15 dias. Todas as amostras foram acondicionadas em sacos plásticos, vedadas, identificadas e encaminhadas ao laboratório de Nematologia da Fundação Chapadão em Chapadão do Sul - MS.

Para extração dos nematóides das raízes foi utilizado o método proposto por Coolen e D'Herde (1972), que consiste na trituração de 10 gramas do material vegetal, peneiramento e centrifugação em solução de sacarose. Na extração dos nematóides do solo o método utilizado foi o proposto por Jenkins (1964), de flutuação, sedimentação, peneiramento e separação por centrífuga em solução de sacarose.

As contagens e identificações dos nematóides foram realizadas com auxílio de câmara de Peters com 1,0 mL da solução, sob microscópio óptico. A identificação foi baseada nas diferenças das características morfológicas das espécies, conforme sugerido pela chave de identificação estabelecida por Gonzaga (2006).

\section{Resultados e Discussão}

Observa-se conforme análise do solo que antes da semeadura das culturas ambas as áreas experimentais apresentaram fitonematóides, sendo o gênero Helicotylenchus Steiner (1945) encontrado em maior quantidade (Figura 1). Figueira et al. (2011) constataram que o sistema pasto e cobertura natural dos solos podem elevar infestações pelo gênero Helicotylenchus, por serem consideradas ótimas hospedeiras alternativas.

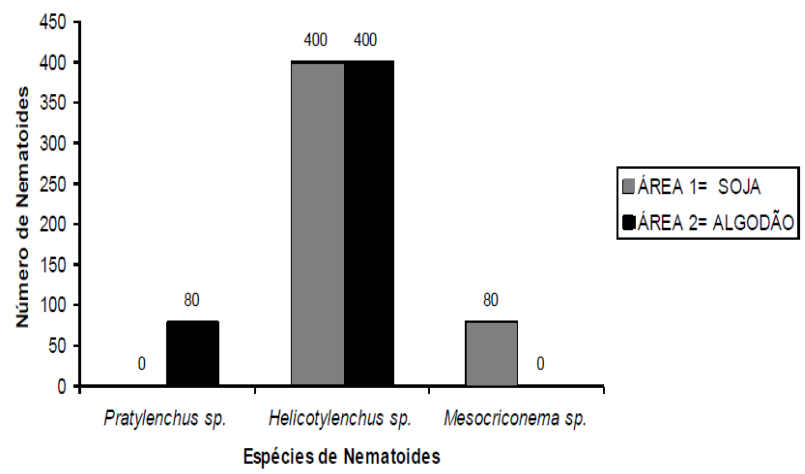

Figura 1. População de nematóides no solo $\left(100 \mathrm{~cm}^{3}\right)$ na semeadura - dezembro de 2011.
Aos 15 dias após a semeadura (DAS) observou-se massa de ovos presentes; 20 ovos no solo, cultivo de soja e 200 ovos na raiz de algodão (Tabela 2). Verificou-se alta infestação de Pratylenchus brachyurus havendo 2.000 indivíduos $/ 10 \mathrm{~g}$ de radicelas de algodão, 560/10 g de radicelas de soja e 20 indivíduos $/ 100 \mathrm{~cm}^{-3}$ de solo em soja (Tabela 2). A presença de Pratylenchus brachyurus foi constatada na área a partir da primeira amostragem infestando a área de cultivo, porém, em valores abaixo do nível de dano, ao contrário do encontrado na amostragem realizada aos 15 DAS. Este fato pode estar ligado provavelmente à multiplicação deste inóculo inicial já que gramíneas forrageiras apresentam grande capacidade de promover a reprodução de alguns fitonematóides, dentre eles o nematóide das lesões radiculares, Pratylenchus brachyurus (Godfrey) Filipjev e S. Stekhoven (GOULART, 2008). De acordo com Goulart e Ferraz (2003), este fitonematóide é caracterizado como polifágo, tal fato explica a rápida adaptação às novas culturas implantadas na área experimental.

Houve menor população de nematóides do gênero Helicotylenchus em solo cultivado com a cultura do algodão, quando comparando com a taxa encontrada no momento da semeadura (Tabela 2). Fato este que pode estar relacionado com a retirada da pastagem e das plantas daninhas e a substituição pelas culturas de algodão e soja. Algumas espécies de nematóides certamente não se adequaram aos novos sistemas de uso da terra e consequentemente houve a diminuição do seu nível populacional (MATTOS et al., 2006).

Ao contrário do observado no gênero Helicotylenchus a espécie $P$. brachyurus foi beneficiada pela mudança no sistema de produção e aos 30 DAS verifica-se um aumento de indivíduos; $72,55 \%$ em soja e $16,66 \%$ em algodão (Tabela 2). Observa-se que as variedades de soja (BMX Potência RR) e de algodão (FMT 701) aliadas às características do solo local (Neossolo Quartzarênico), de textura arenosa, podem ter contribuído para a ocorrência deste pico populacional (Tabela 2).

Observa-se a presença de Pratylenchus zeae, tanto nas raízes como no solo das duas áreas amostradas, onde houve maior população em soja apresentando 1440 indivíduos/ $10 \mathrm{~g}$ (Tabela 2). A presença de $P$. zeae não é comum em áreas de cultivo de algodão e soja, pois geralmente estão associados às espécies de gramíneas como o milho e a cana-de-açúcar que são as culturas mais atacadas, ocasionando seu declínio produtivo (TARTÉ et al., 1997).

Aos 45 DAS obteve-se uma redução na massa de ovos encontrada no solo e raízes de soja e algodão (Tabela 2). A população Pratylenchus sp. foi considerada elevada nas raízes de soja e algodão: 2.150 indivíduos/10 g e 480 indivíduos $/ 10 \mathrm{~g}$ respectivamente. 
Tabela 2. Ocorrência e dinâmica populacional de nematóides associados às culturas de algodão e soja no município de CassilândiaMS, na safra 2011/2012.

\begin{tabular}{|c|c|c|c|c|c|c|c|c|c|c|c|c|c|c|c|c|}
\hline \multirow[t]{3}{*}{ Nematóides } & \multicolumn{16}{|c|}{ Algodão } \\
\hline & \multicolumn{2}{|c|}{15 DAS } & \multicolumn{2}{|c|}{$30 \mathrm{DAS}$} & \multicolumn{2}{|c|}{45 DAS } & \multicolumn{2}{|c|}{60 DAS } & \multicolumn{2}{|c|}{75 DAS } & \multicolumn{2}{|c|}{$90 \mathrm{DAS}$} & \multicolumn{2}{|c|}{105 DAS } & \multicolumn{2}{|c|}{120 DAS } \\
\hline & Solo & Raiz & Solo & Raiz & Solo & Raiz & Solo & Raiz & Solo & Raiz & Solo & Raiz & Solo & Raiz & Solo & Raiz \\
\hline Ovos & - & 200 & 40 & 160 & - & 80 & 20 & 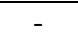 & - & 120 & - & 60 & - & - & 20 & - \\
\hline Pratylenchus sp. & - & - & - & - & 40 & 480 & 20 & 600 & 40 & 440 & - & - & - & - & - & - \\
\hline P. zea & - & - & 150 & 160 & - & - & - & - & - & - & - & - & - & - & - & - \\
\hline P. brachyurus & - & 2000 & - & 2400 & - & - & - & - & - & - & 20 & 640 & 40 & 140 & 100 & 70 \\
\hline Heterodera sp. & - & - & - & - & - & 80 & - & - & - & - & - & - & - & - & - & - \\
\hline Helicotylenchus sp. & 50 & - & - & - & 100 & - & - & - & - & - & - & - & - & - & - & - \\
\hline \multicolumn{17}{|c|}{ Soja } \\
\hline Ovos & 20 & - & - & 320 & 10 & 70 & - & - & - & 1360 & - & 1440 & - & 350 & 40 & 1800 \\
\hline Pratylenchus sp. & - & - & - & - & 20 & 2150 & 10 & 2400 & 60 & 5100 & - & - & - & - & - & - \\
\hline P. zea & - & - & 140 & 1440 & - & - & - & - & - & - & - & - & - & - & - & - \\
\hline P. brachyurus & 20 & 560 & - & 2040 & - & - & - & - & - & - & 20 & 2880 & 20 & 2250 & 100 & 1680 \\
\hline Meloidogyne sp. & - & - & - & - & - & - & - & - & 40 & 80 & - & 1560 & - & 75 & 20 & 1450 \\
\hline Heterodera sp. & - & - & - & - & - & 50 & - & - & - & - & - & - & - & - & - & - \\
\hline
\end{tabular}

O gênero Heterodera sp. apresentou números abaixo de níveis de dano em ambas as culturas (Tabela 2). Cunha et al. (2008) verificaram que em condições ideais de temperatura o ciclo completo do Heterodera está em torno de 21 a 25 dias, período este que ocorre a penetração nas raízes. Possivelmente, a temperatura estava acima da ideal, e consequentemente o ciclo se completou tardiamente, ocasionando seu surgimento neste período do experimento.

Nas amostras de 60 DAS (Tabela 2) a presença de alguns gêneros de fitonematóides foi nula ocorrendo apenas Pratylenchus sp. que aumentou consideravelmente para ambas culturas enquanto no solo houve uma redução. A utilização do método de plantio direto e a alta umidade do solo, ocasionada por chuvas nesta época do ano, pode ter ocasionado a elevação da infestação deste gênero.

Após 75 DAS (Tabela 2), observa-se um aumento de ovos quando comparado às análises anteriores tendo 1.360 nas raízes de soja e 120 nas raízes de algodão. Os fitonematóides do gênero Pratylenchus sp. aumentaram nas raízes da cultura da soja, chegando a 5.100 indivíduos/10 $\mathrm{g}$ de raiz, no entanto para a cultura do algodão houve pequena redução em termos populacionais.

Nesta amostra (75 DAS) observa-se pela primeira vez o surgimento dos nematóides do gênero Meloidogyne sp. infestando a cultura da soja, por sua vez o algodão ficou imune por se tratar do cultivar tolerante FMT 701. Galbieri et al. (2009) estudando o comportamento de diferentes variedades de algodão em relação ao Melodoigyne, constatou que as variedades IPR 140, IRP JATAÍ e FMT 701 são tolerantes.

$\mathrm{Na}$ análise realizada aos 90 DAS (Tabela 2) verificase a presença de ovos nas raízes de ambas as culturas, mantendo-se em níveis parecidos com a da amostra anterior. A população de $P$. brachyurus apresentou um declínio na quantidade de indivíduos tanto na raiz quanto no solo, observando-se 2.880 na raiz da soja e 640 na raiz do algodão.

Quanto ao gênero Meloidogyne sp. houve grande aumento nas raízes de soja, com $1.560 / 10 \mathrm{~g}$ de raiz, considerado um patógeno com alta capacidade reprodutiva, o que gera um rápido crescimento de sua população no campo aliado ao fato de serem espécies perfeitamente adaptadas às condições edafoclimáticas brasileiras (FERRAZ, 1985). Nesta fase, provavelmente, houve a eclosão do estágio juvenil atingindo a fase infectiva, onde o nematoide migra pelo solo e encontra a raiz do hospedeiro (CAMPOS et al., 2006).

Aos 105 DAS (Tabela 2) foram encontrados ovos somente nas raízes de soja 350 ovos/10 g. Em relação à infestação dos nematóides $P$. brachyurus no solo houve baixa ocorrência, já nas raízes a população manteve-se com números elevados atingindo 2.250 indivíduos $/ 10 \mathrm{~g}$ em soja e 140 indivíduos/10 g em algodão. Segundo Silva et al. (2004), o P. brachyurus pode parasitar as plantas tanto no estágio juvenil quanto adulto, isso explicaria a observação deste patógeno na maioria das amostras realizadas.

Observou-se em soja que o gênero Meloidogyne sp. obteve uma redução populacional, apresentando apenas 75 indivíduos $/ 10 \mathrm{~g}$ de raízes. Campos et al. (2006) asseguram que estes indivíduos mesmo antes de estabelecer a alimentação em uma raiz, no estádio juvenil 2, dependem principalmente do teor lipídico de seu corpo para sobreviver. No decorrer dos dias está reserva vai sendo consumida gradativamente e consequentemente o poder infectivo diminui, sendo este fato uma das razões da diminuição expressiva em relação a amostra de 90 dias.

Aos 120 DAS (Tabela 2) observa-se um aumento do número de ovos na cultura da soja; $1.800 / 10 \mathrm{~g}$ de raízes. Este fato pode estar ligado à maturidade fisiológica da 
cultura, no qual sem alimento algumas espécies de nematóides buscam sua sobrevivência através de massa de ovos dormentes. Durante este período o metabolismo se mantém baixo, permitindo-lhes que sobrevivam por longo tempo em condições adversas tais como falta de alimento, água, oxigênio ou temperaturas baixas (CURTIS et al., 2009).

Com relação aos nematóides $P$. brachyurus houve um declínio em sua quantidade nas raízes de algodão, porém na soja os valores encontrados foram de 1.680 indivíduos/10 g. A justificativa da existência de nematóides deste gênero em todas as amostras, se deve a diversos fatores, dentre eles a utilização do método de plantio direto e a umidade do solo (GOULART, 2008). A época de chuvas constantes que compreendeu o período de ensaio influencia diretamente na umidade do solo, tornando o ambiente propício para a propagação dos nematóides da espécie $P$. brachyurus.

Houve expressivo aumento do gênero Meloidogyne sp. nas raízes e no solo de soja com 20 indivíduos/100 $\mathrm{cm}^{-3}$ e 1.450 indivíduos/10 g de raízes. A hipótese provável relacionada a este aumento populacional pode estar ligado ao início de um novo ciclo de vida do patógeno, pois segundo Ferraz (2001) o ciclo de vida dos nematóides do gênero Meloidogyne completa-se geralmente sob temperatura de $27{ }^{\circ} \mathrm{C}$ entre os 22 a 30 dias.

\section{Conclusões}

Os gêneros e espécies de nematóides encontrados nas culturas de soja e algodão foram: Pratylenchus sp., $P$. zeae, $P$. brachyurus, Heterodera sp. $\mathrm{O}$ gênero Helicotylenchus sp. infectou somente o algodão e Meloidogyne sp. e Mesocriconema sp. infectaram exclusivamente a soja.

O gênero Pratylenchus esteve presente em ambas às culturas estudadas, durante todo o período avaliado (120 dias).

\section{Referências Bibliográficas}

AGUIAR, P. FMT-701 um sucesso absoluto! RondonopolisMT: Fundação MT, 2007. 5p. (Boletim informativo bimestral$\left.\mathrm{n}^{\circ} 19\right)$.

ASMUS, G. L. Ocorrência de Nematóides Fitoparasitos em Algodoeiro no Estado de Mato Grosso do Sul. Nematologia Brasileira, Piracicaba-SP, v. 28, n. 1, p. 77-86, 2004.

\section{BRASMAX GENÉTICA LTDA. Região Cerrado: BRASMAX POTENCIA RR. Disponível em: http://brasmaxgenetica.com.br/cultivar/regiao- cerrado/produto/30. Acesso: 19/julho/2015.}

GONZAGA, V. Caracterização morfológica, morfométrica e multiplicação in vitro das seis espécies mais comuns de
Pratylenchus Filipjev, 1936 que ocorrem no Brasil. 2006. 79 f. Tese (Doutorado) - Universidade Estadual Paulista, Faculdade de Ciências Agrárias e Veterinárias, Jaboticabal-SP, 2006

CAMPOS, H. D.; CAMPOS, V. P.; POZZA, E. A. Efeito do tempo, substrato e temperatura na penetração de juvenis do segundo estádio de Meloidogyne javanica e Heterodera glycines em soja. Summa Phytopathologica, Botucatu-SP, v. 32, n. 2, p. 156-160, 2006

CONAB. COMPANHIA NACIONAL DE ABASTECIMENTO. Acompanhamento da safra Brasileira grãos, Safra 2014/15 - Décimo Levantamento. Brasília-DF: 2015. Disponível em: http://www.conab.gov.br/OlalaCMS/uploads/arquivos/15_07_ 09_08_59_32_boletim_graos_julho_2015.pdf. Acesso em: 15 de junho de 2015 .

COOLEN, W. A; D'HERDE, C. J. A method for the quantitative extraction of nematodes form plant tissue. Ghent: State agriculture Research Center, 1972. p.77.

CUNHA, R. P.; MAIA, G. L.; RODACKI, M. E. P.; SILVA, G. S.; MEYER, M. C. Ciclo de vida de Heterodera glycines raça 9 em soja no Estado do Maranhão. Summa Phytopathologica, Botucatu-SP, v. 34, n. 3, p. 262-264, 2008.

CURTIS, R. H. C.; ROBINSON, A. F.; PERRY, R. N. Hatch and host location. In: PERRY, R. N.; MOENS, M.; STARR, J. (eds). Root-knot nematodes. Wallingford, UK, CABI Plublishing, 2009. p. 139-162.

DAVIDE, R. G. Nematode survey and collection of samples. In: F.S. DELA CRUZ JR., I. VAN DEN BERGH, D. DE WAELE, D.M. HAUTEA and A.B. MOLINA (Eds.). Towards management of Musa nematodes in Asia and the Pacific. Technical... Los Baños: Inibap, p. 3-6. 2003.

EMBRAPA. EMPRESA BRASILEIRA DE PESQUISA AGROPECUÁRIA. Sistema brasileiro de classificação de solos. Centro Nacional de Pesquisa de Solos. Brasília-DF, 1999. $412 \mathrm{p}$.

EMBRAPA. EMPRESA BRASILEIRA DE PESQUISA AGROPECUÁRIA. Tecnologias de produção de sojaRegião Central do Brasil 2012 e 2013. Centro Nacional de Pesquisa de Soja. Londrina-PR: Embrapa Soja, 2011, 261 p. (Sistemas de Produção, 15).

FERRAZ, L. C. C. B. As meloidoginoses da soja: passado, presente e futuro. In: SILVA, J. F. V. (Org.). Relações parasito-hospedeiro nas meloidoginoses da soja. LondrinaSP: EMBRAPA Soja; Sociedade Brasileira de Nematologia, 2001. p. 15-38.

FERRAZ, S. Summary report on the current status, progress and needs for Meloidogyne research in Brazil (Region III). In: SASSER, J. N.; CARTER, C.C. (Ed.). An advanced treatise on Meloidogyne. Volume I: Biology and control. Raleigh: North Caroline State University Graphics, 1985. p. 351-352.

FIGUEIRA, A. F.; BERBARA, R. L. L.; PIMENTEL, J. P. Estrutura da população de nematóides do solo em uma unidade de produção agroecológica no Estado do Rio de Janeiro, Brasil. Acta Scientiarum Agronomy, Maringá- PR, v. 33, n. 2, p. 223229, 2011. 
GOUlART, A. M. C.; FERRAZ, L. C. C. B. Comunidade de nematóides em Cerrado com vegetação original preservada ou substituída por culturas. Nematologia Brasileira, PiracicabaSP, v. 27, n. 2 p. 129-137, 2003.

GOULART, A. M. C. Aspectos gerais sobre Nematóides-daslesões radiculares (gênero Pratylenchus). Planaltina-DF: Embrapa Cerrados, 2008. 27p. (Documentos 219).

INOMOTO, M. M. Principais nematóides na cultura da soja e seu manejo. Monsanto em Campo, Piracicaba-SP, v. 7, n. 1, $\mathrm{s} / \mathrm{p}, 2006$.

JENKINS, W. R. A rapid centrifugal- flotation technique for separating nematodes from soil. The Plant Disease Reporter, Washington-USA, v. 48, n. 6, p. 692, 1964.

MATTOS, J. K. A.; HUANG, S. P.; PIMENTEL, C. M. M. Grupos tróficos da comunidade de nematóides do solo em oito sistemas de uso da terra nos cerrados do Brasil Central. Nematologia Brasileira, Piracicaba-SP v. 30, n. 3, p. 267-273, 2006.
GALBIERI, R.; FUZATTO, M. G.; CIA, E.; LÜDERS, R. R.; MACHADO, A. C. Z.; BOLDT, A. F. Reação de cultivares de algodoeiro a Meloidogyne incógnita em condições de campo e casa de vegetação no estado de Mato Grosso. Tropical Plant Pathology, Brasília-DF, v. 34, n.1, p. 18- 23, 2009.

SILVA, R. A.; SERRANO, M. A. S.; INOMOTO, M.M.; ASMUS, G. L. Distribuição populacional e danos provocados por Meloidogyne incógnita, Rotylenchulus reniformis e Pratylenchulus brachyurus na cultura do algodoeiro no estado de Mato Grosso. Várzea Grande-MT, $2004 . \quad$ Disponível em: http://antigo.facual.org.br/pesquisa/arquivos/Relatorio_Nemat oide.pdf. Acessado em: 03/julho/2015.

TARTÉ, R.; CERRUD, D.; RODRIGUEZ, I.; OSORIO, J. M. Presencia y parasitismo de Pratylenchus zeae em cana de azucar em Panamá com indicaciones sobre La susceptibilidad relativa de algunos cultivares. Turrialba, San Jose, v. 27, p. 259-266, 1997. 